\title{
SATELLITE IMAGERY DRIVEN ASSESSMENT OF LAND USE LAND COVER, URBANIZATION AND SURFACE TEMPERATURE PATTERN DYNAMICS OVER TROPICAL MEGACITIES
}

\author{
Subhrant Verma ${ }^{1}$, Sonam Agrawal ${ }^{2, *}$, Kanaya Dutta ${ }^{2}$ \\ ${ }^{1}$ GIS Cell, Motilal Nehru National Institute of Technology Allahabad, Prayagraj, Uttar Pradesh 211004, India - \\ subhrantverma.sv@gmail.com \\ ${ }^{2}$ GIS Cell, Motilal Nehru National Institute of Technology Allahabad, Prayagraj, Uttar Pradesh 211004, India - (sonam, \\ rgi1604)@mnnit.ac.in
}

KEY WORDS: Land Use Land Cover, Land Surface Temperature, Shannon's Entropy, Delhi, Bengaluru.

\begin{abstract}
:
In most of the developing nations, fast paced urbanisation is going on. This has changed the spatial patterns of Land Use Land Cover (LULC) and Land Surface Temperature (LST) over time. Continual studies are required in this context to know these phenomena more clearly. This study is carried out to analyse the spatio-temporal changes in LULC, urbanisation and LST in the metropolitan cities of India namely Delhi and Bengaluru. Landsat images of TM and OLI sensors are taken for the years 2001,2010 and 2020. The LULC layer is obtained through supervised image classification. Concentric circles at the interval of $2 \mathrm{~km}$ are drawn from the centroid of the study areas which are used to compute Shannon's entropy through zonal analysis of the reclassified LULC layer. The thermal band of the Landsat is used for the computation of LST. The results of both the study areas revealed 1) decline in the open land, vegetation and water body; 2) rampant growth of built-up and urban area which become more compact over the years; and 3) spread of the higher LST zones.
\end{abstract}

\section{INTRODUCTION}

Urbanisation is the driving force of land cover modifications. All over the world, drastic conversion of vegetation, water bodies and agricultural land into paved surfaces is taking place. A similar scenario is prominent in and around various cities of India. India is a highly populated country with continuous migration of people towards city regions (Shastri et al., 2017). The population pressure has resulted in the rapid spread of urban built-up, in both planned and unplanned manner. This substantial growth of impervious surfaces has an impact on urban micro climate (Ramachandra and Kumar, 2009). Lack of vegetation and water bodies reduces heat loss through evapotranspiration (Soltani and Sharifi, 2017). On the other hand, concrete surfaces and reflective facets of urban built-up lead to trapping of heat and rise of local temperature (Cilek and Cilek, 2021). The presence of high rise buildings also hinders wind flow. The anthropogenic activities further contribute to the increase in local surface temperature.

The Land Surface Temperature (LST) of urban sectors remains much higher than the LST of surrounding rural or natural land covers at the same point of time (Dutta et al., 2018; Mahmoodi et al., 2019). This micro level climatic phenomenon resulted from urbanization is termed as the Urban Heat Island (UHI) (Oke, 1973). These zones of extremely high LST can be mapped from the spatial dataset of temperature patterns. Timely monitoring of the local LST pattern is a prime requisite of urban environmental studies. High LST and the presence of UHI create numerous health problems through thermal discomfort, heat stress, heat stroke etc. High LST over cities also increases the cooling needs and eventually energy consumptions (Falasca et al., 2019). Studies of LST patterns have thus gained importance to improve urban health conditions and maintain sustainability. Monitoring the LST pattern spatially and temporally has become manageable with the availability of remote sensing datasets. Satellite images are readily available and reliable sources of surface information (Agrawal and Khairnar, 2019). LST information can be procured by processing the thermal bands of satellite images.

Assessing critical LST conditions is incomplete without analysing the causes behind their spatio-temporal pattern. The nature of LST distribution and growth of UHIs is closely related to other surface properties, like the nature of the land cover. Hence, studying Land Use Land Cover (LULC) patterns and their changes over time is of primary importance to urban researchers (Agrawal and Gupta, 2017). LULC describes the features naturally present over land and the associated anthropogenic activities shaping the land (Dutta et al., 2021). Dynamicity of LULC is often investigated to explain the current LST scenario and also to prevent a further rise in temperature (Saha et al., 2020). Similar to LST, LULC maps can also be prepared by combining different satellite bands. Many studies have depicted that out of various types of land cover; the impervious built-up spread has maximum effects in the form of local climate alterations. Hence, temporal maps showing the growth of paved surfaces are of notable importance. The sprawl of urban built-up from the central parts of a city can be quantified using various methods. One of the most prominent ways to evaluate sprawl is through Shannon entropy computation. Shannon's entropy draws its concept from information theory. The dispersion rate of urban sprawl is quantified by considering impervious built-up as a parameter (Biney and Boakye, 2021).

The rising LST is a critical problem in tropical climates (Sultana and Satyanarayana, 2020). Especially in fastdeveloping city regions of India, which are highly prone to

\footnotetext{
* Corresponding author
} 
LULC and climate alterations. So, there is a continuous requirement for empirical datasets to model urban growth and urban climate. It is necessary to frequently monitor the changing climate patterns, which have significant ill effects on city dwellers. Other researches solely studying local temperature patterns do not identify areas prone to risk by future urban sprawl (Hua et al., 2012). Hence, combining the nature of urban sprawl and associated temperature patterns is needed. Also, studies based on a single city do not give the entire picture of differential rates of urban sprawl occurring in different cities. The local climate may also vary based on geographical setting and location. This asks for consideration of more than one city for a better understanding of urban dynamics. With respect to these research gaps and requirements, the current study is carried out, which is focused on two tropical mega cities of India namely, New Delhi and Bangalore.

The first objective of the study was to analyse spatial patterns of LULC for the respective study regions over a time period of two decades. The second objective was to statistically quantify urban sprawl using Shannon entropy and visualize the inter-city rate and direction of urbanization. The final objective of the work was to procure surface temperature information from satellite images and link LST maps with dynamic urban growth patterns. The study attempts to provide timely and accurate surface data to urban planners and developers for sustainable planning of suburbs and remodelling of dense urban built-up.

\section{STUDY AREA}

Delhi and Bengaluru are selected as the study area of this work, as shown in Figure 1. These regions are considered as they are metropolitan areas with urban agglomerations. These locations need to be studied as they witnessed rapid industrialization and urbanization over the past two decades. The geographical extent of Delhi is from $76^{\circ} 50^{\prime} 38.4^{\prime \prime} \mathrm{E}$ to $77^{\circ} 20^{\prime} 42^{\prime \prime}$ E longitude and from $28^{\circ} 24^{\prime} 7.2^{\prime \prime} \mathrm{N}$ to $28^{\circ} 53^{\prime}$ 13.2" $\mathrm{N}$ latitude. It covers an area of $1490.09 \mathrm{~km}^{2}$. Its population was $13,850,507$ in the year 2001 , which increased to $16,787,941$ by the year 2011 . This region is very densely populated. The population density was 9,340 people per $\mathrm{km}^{2}$ in 2001 , which reached 11,320 people per $\mathrm{km}^{2}$ by 2011 . It is quite higher than the national average, which is 382 people per $\mathrm{km}^{2}$. Being the most significant urban centre of north India, this region is densely built and has witnessed rapid urban sprawl around it in recent times. It has a humid subtropical climate with extreme temperature variation in the summer and winter seasons.

The geographical extent of Bengaluru is from $77^{\circ} 10^{\prime} 55.2^{\prime \prime} \mathrm{E}$ to $77^{\circ} 57^{\prime} 54^{\prime \prime} \mathrm{E}$ longitude and from $12^{\circ} 39^{\prime} 28.8^{\prime \prime} \mathrm{N}$ to $13^{\circ}$ 29' $56.4^{\prime \prime} \mathrm{N}$ latitude. Its area is $4151.30 \mathrm{~km}^{2}$. In the year 2001 , its population was $6,537,124$ which increased to $9,621,551$ by 2011. This region has experienced drastic urban growth as the centre of IT hub, educational institutions and many other industries in current decades. Bengaluru is known as the silicon valley of India as it is a hub of technology companies. It has a tropical savannah climate with an average yearly temperature of $23.9^{\circ} \mathrm{C}$.

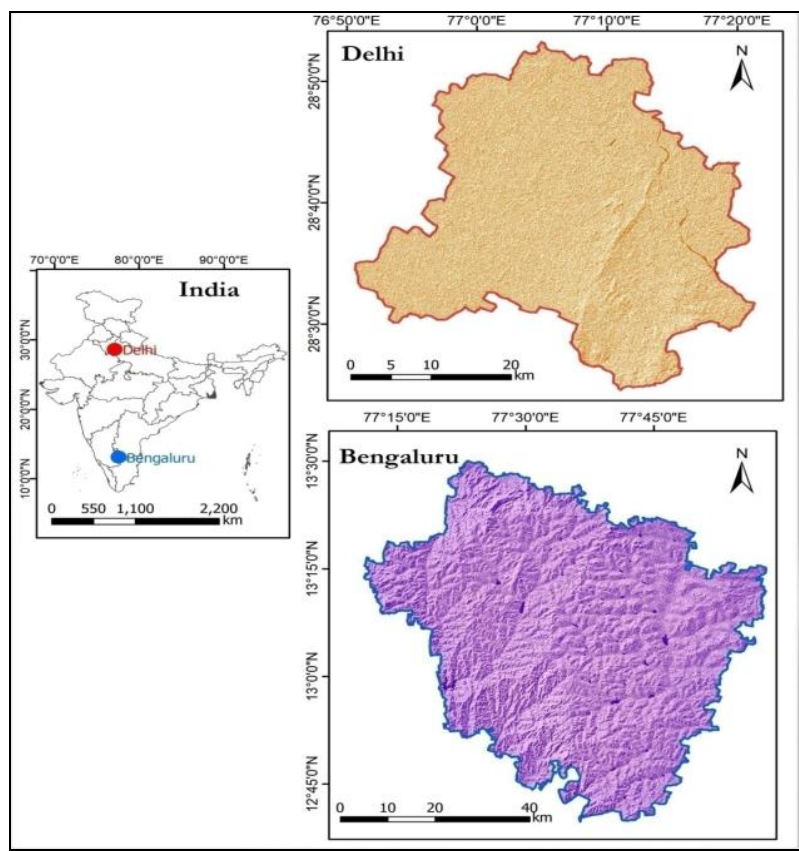

Figure 1. Study area location and extend.

\section{DATA USED}

Survey of India (SOI) topographic maps and Landsat satellite images are used in the current work. Open series maps are freely downloaded from the Nakshe portal of SOI. These maps have WGS-84 datum and UTM projection. The scale of maps is 1:50000. Delhi is covered in eight maps whose sheet numbers are H43W13, H43W14, H43X1, H43X2, H43X3, $\mathrm{H} 43 \mathrm{X} 5, \mathrm{H} 43 \mathrm{X} 6$ and H43X. Bengaluru is covered in thirteen maps whose sheet numbers are D43R16, D43R12, D43R8, D43X6, D43X9，D43R15，D43X13，D43X5， D43X10, D43X14, D43R3, D43R7 and D43R11. These maps are used to obtain the administrative boundaries of the study areas. Multispectral Landsat satellite images are used for LULC and LST extraction. Landsat 4 Thematic Mapper (TM), Landsat 5 TM and Landsat 8 Operational Land Imager (OLI)/Thermal Infrared Sensor (TIRS) images are used whose details are listed in Table 1. They are freely downloaded from the USGS EarthExplorer portal.

\begin{tabular}{|l|l|l|}
\hline Sensor & Acquisition Date & Path/ Row \\
\hline TM & $05 / 02 / 2001$ & $146 / 40$ (Delhi) \\
TM & $27 / 03 / 2001$ & $144 / 51$ (Bengaluru) \\
TM & $01 / 02 / 2011$ & $146 / 40$ (Delhi) \\
TM & $07 / 03 / 2011$ & $144 / 51$ (Bengaluru) \\
OLI/ TIRS & $10 / 02 / 2020$ & $146 / 40 \& 147 / 40$ (Delhi) \\
OLI/ TIRS & $28 / 02 / 2020$ & $144 / 51$ (Bengaluru) \\
\hline
\end{tabular}

Table 1. Details of satellite images used.

\section{METHODOLOGY}

Figure 2 gives the flowchart of the overall methodology which is described in the following subsections:

\subsection{Data Preparation}

First of all, data collection and processing are done. Each topographic map is georeferenced using first-order affine transformation and the nearest neighbour resampling method. The maps of Delhi and Bengaluru are mosaicked individually 


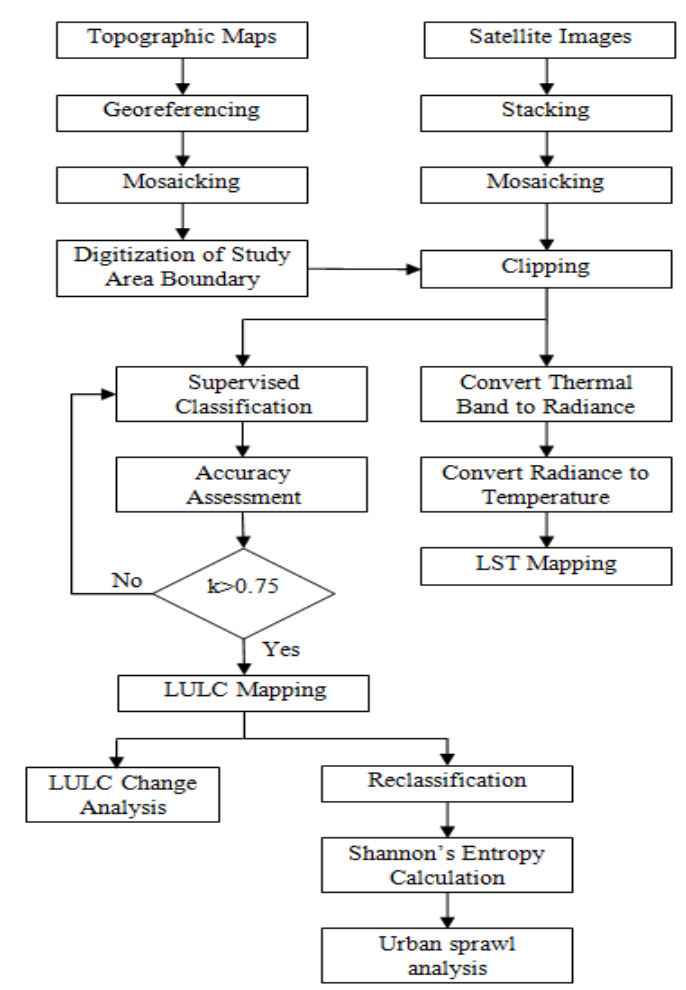

Figure 1. Flowchart of the overall methodology adopted.

to get a single basemap of these study areas. Finally, the boundary of Delhi and Bengaluru is digitized, resulting in the shapefiles that are later used to clip the area of interest from the satellite images. In the first objective, the LULC analysis is carried out over the period of two decades, from 2001 to 2011 and from 2011 to 2020 . Therefore, Landsat images of the year 2001, 2011 and 2020 are used. In the raw Landsat image, several bands are present. Thus, stacking is performed to get the required band combination for LULC classification. Clipping is then performed to extract the study area from the stacked image with the help of a boundary shapefile.

\subsection{Image Classification}

The image classification is performed to obtain the LULC layer. The LULC layer is required to extract the urban or built-up region of the study area. Supervised classification is used for classifying the study area. For this purpose, a maximum likelihood classifier is used. Prior knowledge of the study area is required to perform supervised classification. It starts with the selection of training samples of each LULC class. Training samples are selected with the help of topographical maps, Google Earth and visual analysis of the study area images. In every class, at least ten training areas are taken in a fairly distributed manner as autocorrelation property exists in the spatial data. After that signature file is ready to use for classification. The maximum likelihood classifier assumes that the statistics for each LULC class in every band are normally distributed and calculates the probability that a given pixel belongs to a specific class. Each pixel is entrusted to the class that has the highest probability. The Delhi image is classified into five LULC classes: built-up, forest, open land, vegetation and water. The Bengaluru image is classified into four prominent LULC classes: built-up, open land, vegetation and water. Validation of classification is done by accuracy assessment through kappa coefficient $(\mathrm{k})$ which is calculated by a confusion matrix. If the kappa coefficient value is 0.75 or higher, then classified data is considered to be in agreement with the ground truth and further analysis is performed. Otherwise, classification will be repeated.

\subsection{Shannon's Entropy Computation}

Shannon's entropy is computed to understand urban growth. The classified image is categorized into two classes: urban and non-urban area, through reclassification. Multiple buffer rings are drawn from the study area centre up to the outer boundary at the interval of $2 \mathrm{~km}$. Shannon's entropy value of each zone of an urban area is computed using the following equation:

$$
\mathrm{H}_{\mathrm{n}}=\sum_{i=1}^{n} \mathrm{P}_{\mathrm{i}} \log _{\mathrm{e}}\left(\frac{1}{\mathrm{P}_{\mathrm{i}}}\right)
$$

$$
\begin{array}{ll}
\text { where } & \mathrm{H}_{\mathrm{n}}=\text { Shannon's entropy } \\
& \mathrm{P}_{\mathrm{i}}=\text { percentage of built-up in the } \mathrm{i}^{\text {th }} \text { zone } \\
\mathrm{n}=\text { number of zones }
\end{array}
$$

\subsection{LST Computation}

The LST of the study regions is then computed with the help of a thermal infrared band. The Landsat TM band 6 and OLI band 10 are used for this purpose. By using the clipping tool, the study area is extracted from the raw image. Then the numerical model is used to convert the thermal image into Top of Atmosphere (TOA) radiance image. From the radiance image, the temperature image is calculated by the following formula:

$$
L_{\lambda}=M_{L} Q_{C A L}+A_{L},(2)
$$

where $\quad \mathrm{L}_{\lambda}=$ TOA radiance in Watts $/\left(\mathrm{m}^{2 *} \operatorname{srad}^{*} \mu \mathrm{m}\right)$

$\mathrm{M}_{\mathrm{L}}=$ multiplicative rescaling factor whose value is 0.055375 for TM and 0.0003342 for OLI

$\mathrm{A}_{\mathrm{L}}=$ band-specific additive rescaling factor whose value is 1.18243 for TM and 0.1 for OLI

From the above computed TOA radiance image, the TOA brightness temperature is obtained using the following equation:

$$
T=\frac{K_{2}}{\ln \left(\frac{K_{1}}{L_{\Lambda}}+1\right)}
$$

where $\quad \mathrm{T}=\mathrm{TOA}$ temperature measured in Kelvin $\mathrm{K}_{1}=$ band-specific thermal conversion constant whose value is 607.76 and 774.8853 for TM and OLI sensors, respectively

$\mathrm{K}_{2}=$ band-specific thermal conversion constant whose value is 1260.56 and 1321.0789 for TM and OLI sensors, respectively

Finally, LST is obtained in degree Celsius using the following the equation:

$$
L S T=T-273.15,
$$

where $\quad$ LST $=$ Land surface temperature in degree Celsius $\mathrm{T}=\mathrm{TOA}$ temperature measured in Kelvin 


\section{RESULTS AND DISCUSSION}

\subsection{Delhi Study Area}

5.1.1 Spatio-Temporal Change Analysis of LULC in Delhi: The supervised classification has been performed on the images from 2001 to 2020 at the decadal interval for LULC characterization. LULC results for the years 2001, 2011 and 2020 are shown in Figure 3. In the classified image, five LULC classes have been identified: built-up, forest, open land, vegetation and water that are depicted by red, green, brown, yellow and blue color, respectively. The overall accuracy of $87.86 \%, 82.98 \%$ and $83.98 \%$, and the kappa coefficient of $0.84,0.79$ and 0.79 have been achieved for 2001, 2011 and 2020, respectively. Since the accuracy level of classified maps is satisfactory, the LULC change analysis from these maps is carried out. The area of each class in the classified images of Delhi is shown in Table 2.

\begin{tabular}{|l|l|c|c|c|}
\hline \multirow{2}{*}{ S. No. } & \multirow{2}{*}{ LULC Class } & \multicolumn{3}{|c|}{ Area $\left(\mathbf{k m}^{\mathbf{2}}\right)$} \\
\cline { 3 - 5 } & & $\mathbf{2 0 0 1}$ & $\mathbf{2 0 1 1}$ & $\mathbf{2 0 2 0}$ \\
\hline 1 & Built-up & 454.55 & 513.20 & 803.05 \\
2 & Forest & 227.93 & 154.92 & 223.40 \\
3 & Open land & 348.96 & 363.69 & 72.91 \\
4 & Vegetation & 448.75 & 433.79 & 381.37 \\
5 & Water & 9.90 & 24.49 & 9.34 \\
\hline
\end{tabular}

Table 2. Area of each class in the classified images of Delhi.

A significant increase in the built-up area can be observed over the years. In 2001, built-up was $454.55 \mathrm{~km}^{2}$ which increased to $513.20 \mathrm{~km}^{2}$ in 2011, i.e., there is an increase of $58.65 \mathrm{~km}^{2}$. But compared to the last decade, the expansion of the built-up area from 2011 to 2020 is very high. Between the years 2011 and 2020, the size of built-up increased from $513.20 \mathrm{~km}^{2}$ to $803.05 \mathrm{~km}^{2}$. The vast increment appears in the last decade, which is $289.85 \mathrm{~km}^{2}$.

The built-up area, as well as the vegetation and forest area, have been changed from 2001 to 2011 . The vegetation has been decreased by $3.33 \%$ and the forest area reduced by $32.04 \%$. During the decade of 2011 to 2020 , vegetation area has been again reduced by $12.08 \%$, but the forest area has been increased by $30.59 \%$. The conversion of classes to each other is estimated through a transition matrix. It shows the probability of conversion of one into different classes. In Table 3, it is depicted that a large portion of the forest and open land got converted into built-up for both decades. This conversion is more dominant from 2011 to 2020.

\begin{tabular}{|l|c|c|c|c|c|}
\hline \multicolumn{7}{|c|}{ From 2001 to 2011 } \\
\hline & Built-up & Vegetation & Forest & Open land & Water \\
\hline Built-up & 0.819 & 0.030 & 0.037 & 0.102 & 0.013 \\
Vegetation & 0.036 & 0.752 & 0.040 & 0.167 & 0.005 \\
Forest & 0.225 & 0.157 & 0.394 & 0.198 & 0.026 \\
Openland & 0.207 & 0.134 & 0.086 & 0.561 & 0.012 \\
Water & 0.145 & 0.023 & 0.035 & 0.147 & 0.650 \\
\hline \multicolumn{7}{|c|}{ From 2011 to 2020 } \\
\hline Built-up & Built-up & Vegetation & Forest & Open land & Water \\
Vegetation & 0.913 & 0.015 & 0.054 & 0.016 & 0.002 \\
Forest & 0.148 & 0.738 & 0.095 & 0.018 & 0.001 \\
Openland & 0.248 & 0.066 & 0.613 & 0.072 & 0.001 \\
Water & 0.605 & 0.111 & 0.157 & 0.124 & 0.003 \\
Built-up & 0.487 & 0.114 & 0.101 & 0.029 & 0.270 \\
\hline
\end{tabular}

Table 3. Transition matrix of Delhi for the years 2001-2011 and 2011-2020.
5.1.2 Shannon Entropy in Delhi: This study uses Shannon entropy to quantify the urban sprawl. Urban area extracted from the LULC classification results. After the urban area extraction from the LULC classes, multiple $2 \mathrm{~km}$ buffers are formed from the centre to the city's boundary, as shown in Figure 4 for all the years.

Figure 5 shows the entropy in each of the 15 zones. The starting zones from 1 to 6 indicate compact development and afterward, zones show the urban sprawl phenomena, which is more prominent in the graph line of the year 2020. Shannon entropy value was 2.456 in 2001, 2.458 in 2011 and 2.466 in 2020 , which are close to the upper limit of $\log _{\mathrm{e}}(\mathrm{n})$, i.e. 2.708 . This shows the degree of dispersion of built-up area in the region. These values confirmed a gently increasing rate of the urban area. Shannon's entropy value has been grown continuously for the last two decades. A sharper increment has occurred in the entropy value in the 2011-2020 period compared to the 2001-2011 period. The entropy value indicates the urban sprawl in the city.

5.1.3 LST Change Analysis in Delhi: The spatial variation of LST has been studied from 2001 to 2020. Figure 6 shows the spatial distribution of LST for the years 2001, 2011 and 2020. The high temperature zones have been appeared in shades of red and correspond to built-up areas, open surfaces and barren hill slopes. The cooler zones are portrayed by the shades of blue which are present at the locations corresponding to water bodies, vegetation and agricultural land. The impact of vegetation is clearly seen as low temperature values are observed over agricultural land and dense vegetation (forest) land use categories. The nearby region of the built-up has a barren hilly land cover. Therefore heat islands could be seen at these locations instead of builtup.

\subsection{Bengaluru Study Area}

5.2.1 Spatio-Temporal Change Analysis of LULC in Bengaluru: Bengaluru's LULC results for the years 2001, 2011 and 2020 are shown in Figure 7. A unique color has indicated every class in the map, like red for built-up, yellow for vegetation, brown for open land and blue for water. Accuracy assessment is done to check whether every pixel belongs to the original class for a generated map from any remotely sensed data. Overall accuracy is calculated as $84.72 \%$ for the year $2001,81.34 \%$ for 2011 and $82.56 \%$ for 2020. The kappa coefficients are $0.81,0.75$ and 0.82 for 2001, 2011 and 2020, respectively. The accuracy is satisfactory to carry out post classification assessments of LULC.

\begin{tabular}{|c|l|r|r|r|}
\hline \multirow{2}{*}{ S. No. } & \multirow{2}{*}{ LULC Class } & \multicolumn{3}{|c|}{ Area $\left(\mathrm{km}^{2}\right)$} \\
\cline { 3 - 5 } & & \multicolumn{1}{|c|}{$\mathbf{2 0 0 1}$} & \multicolumn{1}{|c|}{$\mathbf{2 0 2 0}$} \\
\hline 1 & Built-up & 356.29 & 973.84 & 1075.51 \\
2 & Vegetation & 745.53 & 245.12 & 757.52 \\
3 & Open land & 3368.39 & 3274.49 & 2667.31 \\
4 & Water & 37.38 & 14.15 & 7.27 \\
\hline
\end{tabular}

Table 4. Area of each class in the classified images of Bengaluru.

Changes in the LULC areas from 2001 to 2020 are quantified in Table 4. The built-up area was $356.29 \mathrm{~km}^{2}$ in 2001 which has been increased to $973.84 \mathrm{~km}^{2}$ in 2011 . There are $4.52 \%$ urban area contributed to the total urban area in 2001 and this 

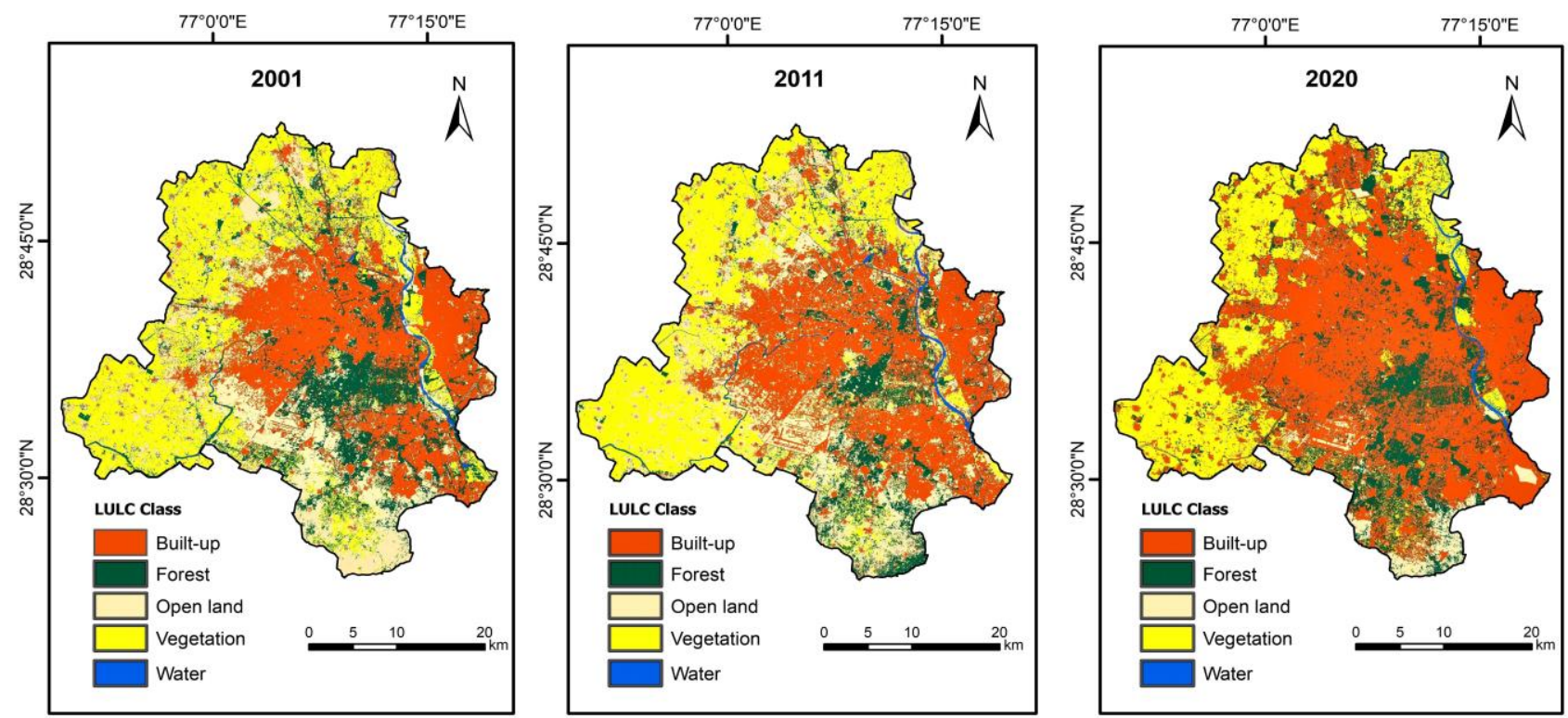

Figure 3. LULC classification results of Delhi.
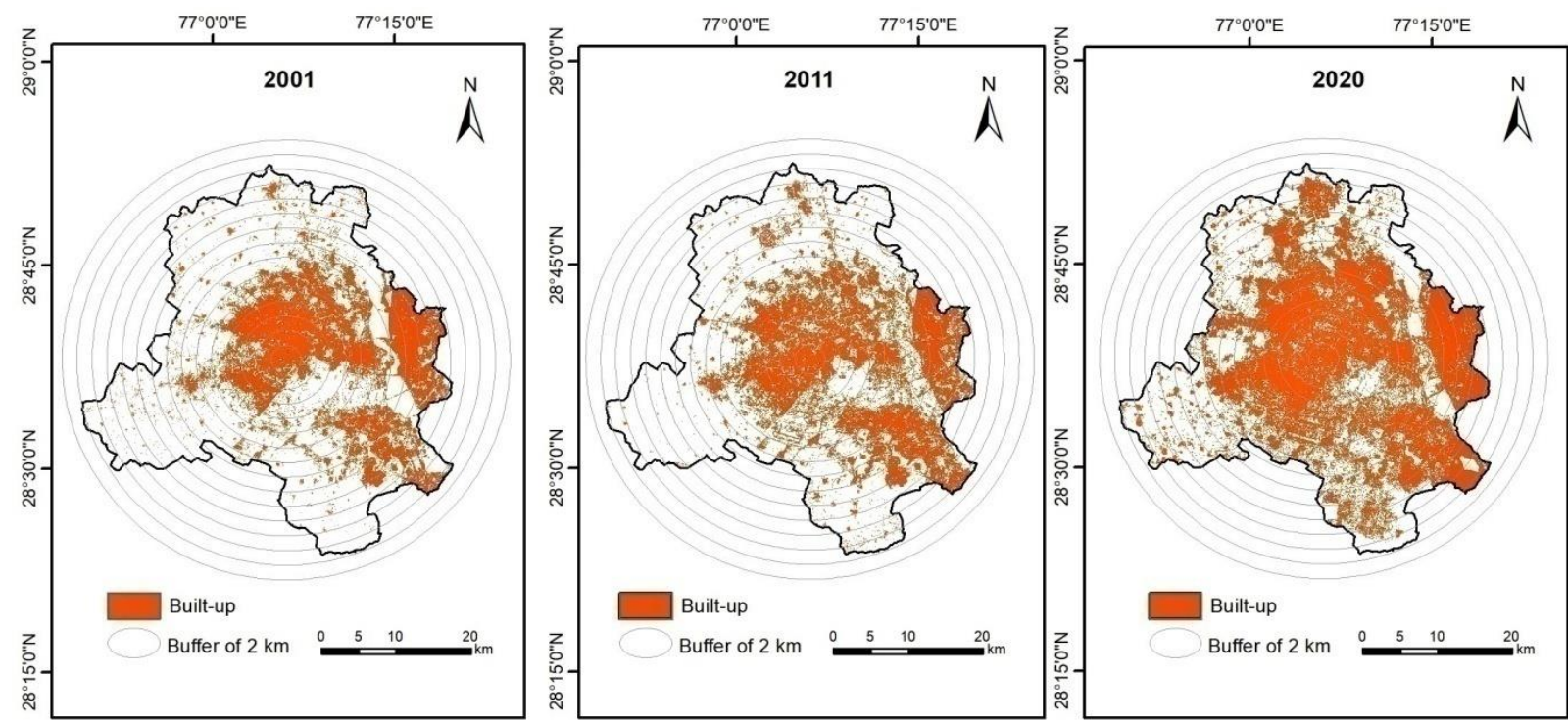

Figure 4. Zone-wise built-up area for years 2001, 2011 and 2020 with a radial distance of $2 \mathrm{~km}$ from the centroid of Delhi.

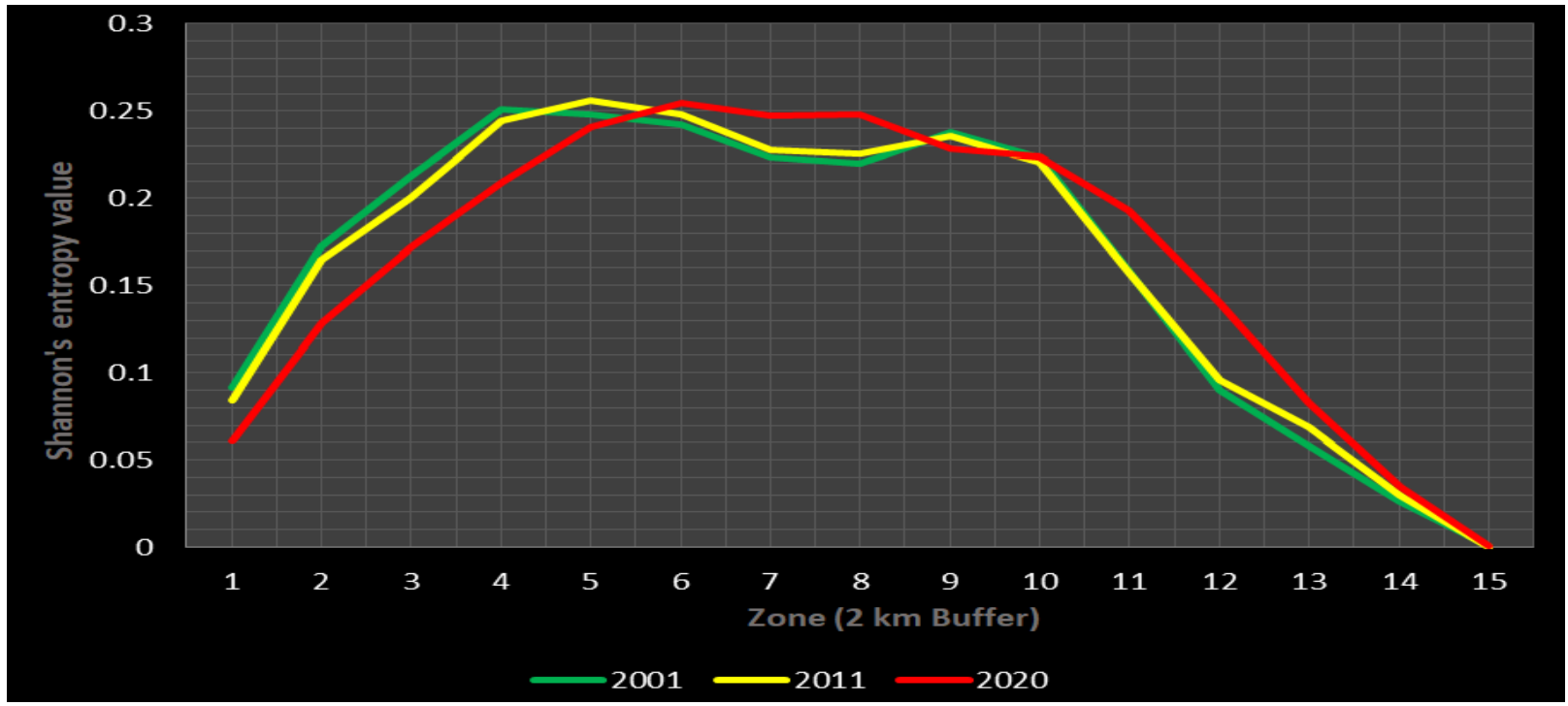

Figure 5. Zone-wise value of Shannon's entropy in Delhi for the years 2001, 2010 and 2020. 

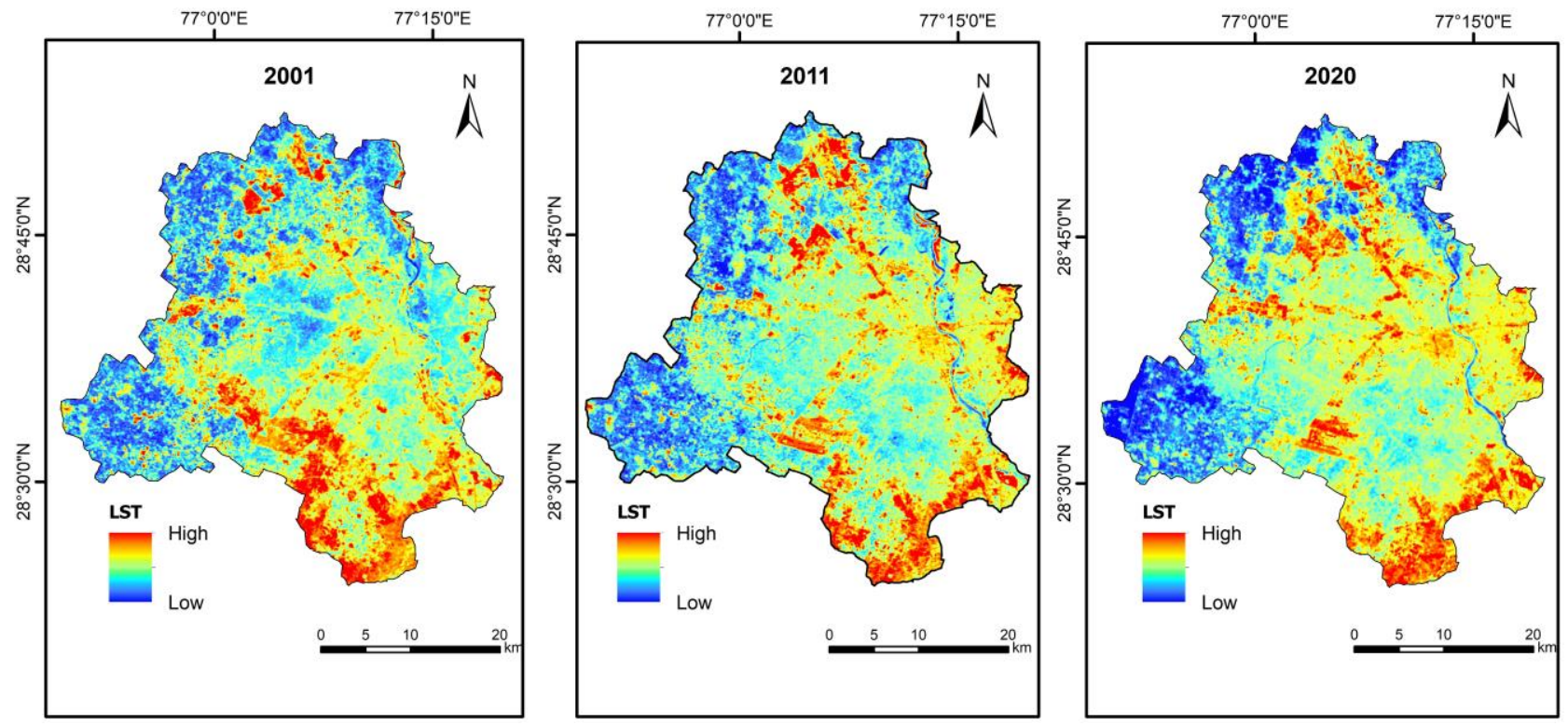

Figure 6. Spatio-temporal pattern of LST in Delhi.
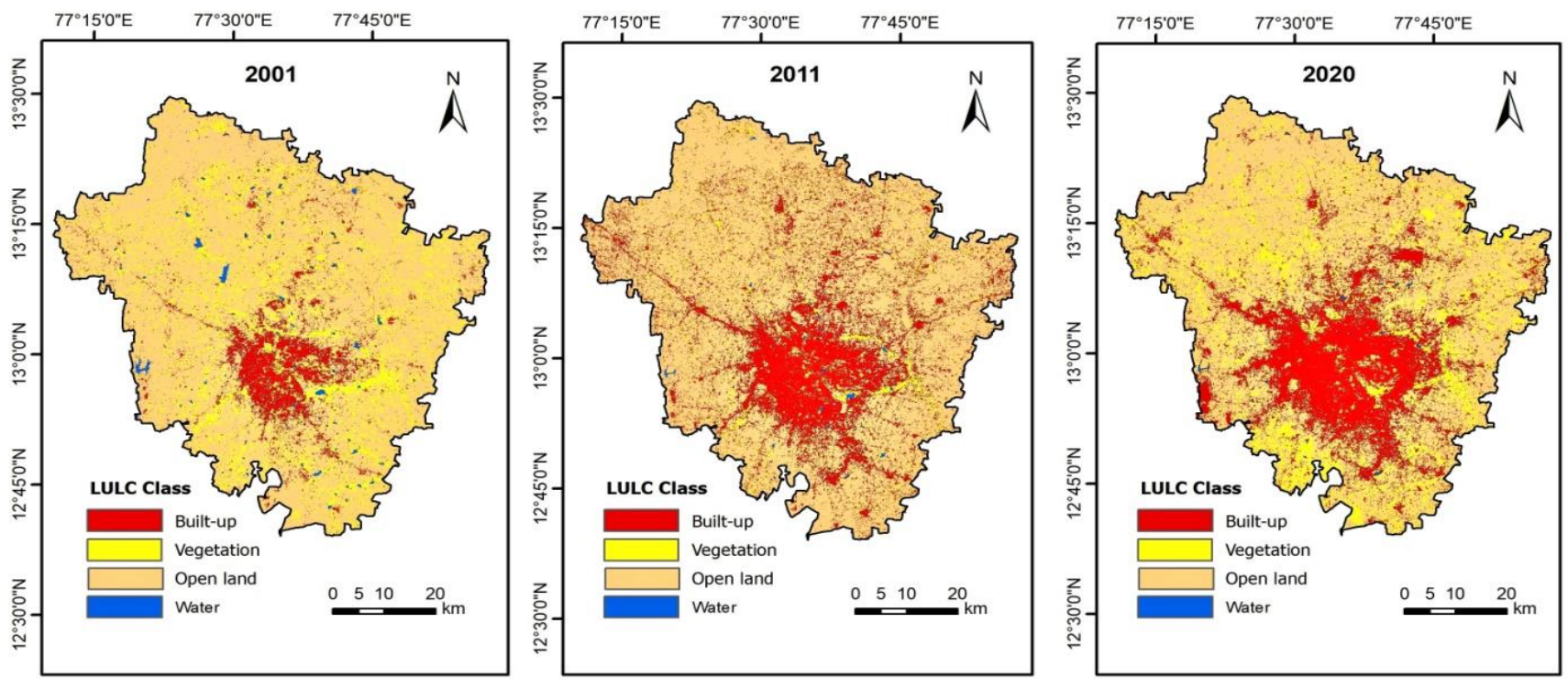

Figure 7. Spatial distribution of LULC in Bengaluru.
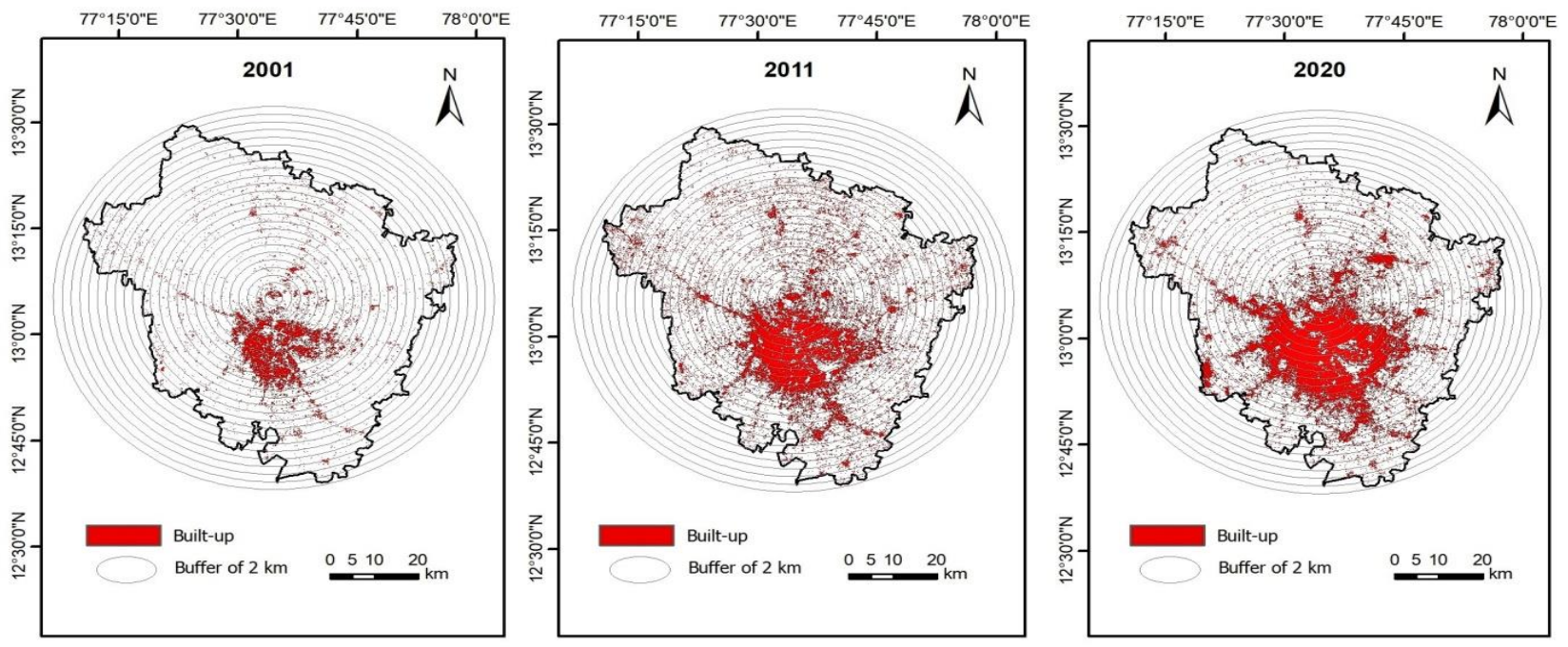

Figure 8. Zone-wise built-up area from 2001 to 2020 within a radial distance of $2 \mathrm{~km}$ from the centroid of Bengaluru. 


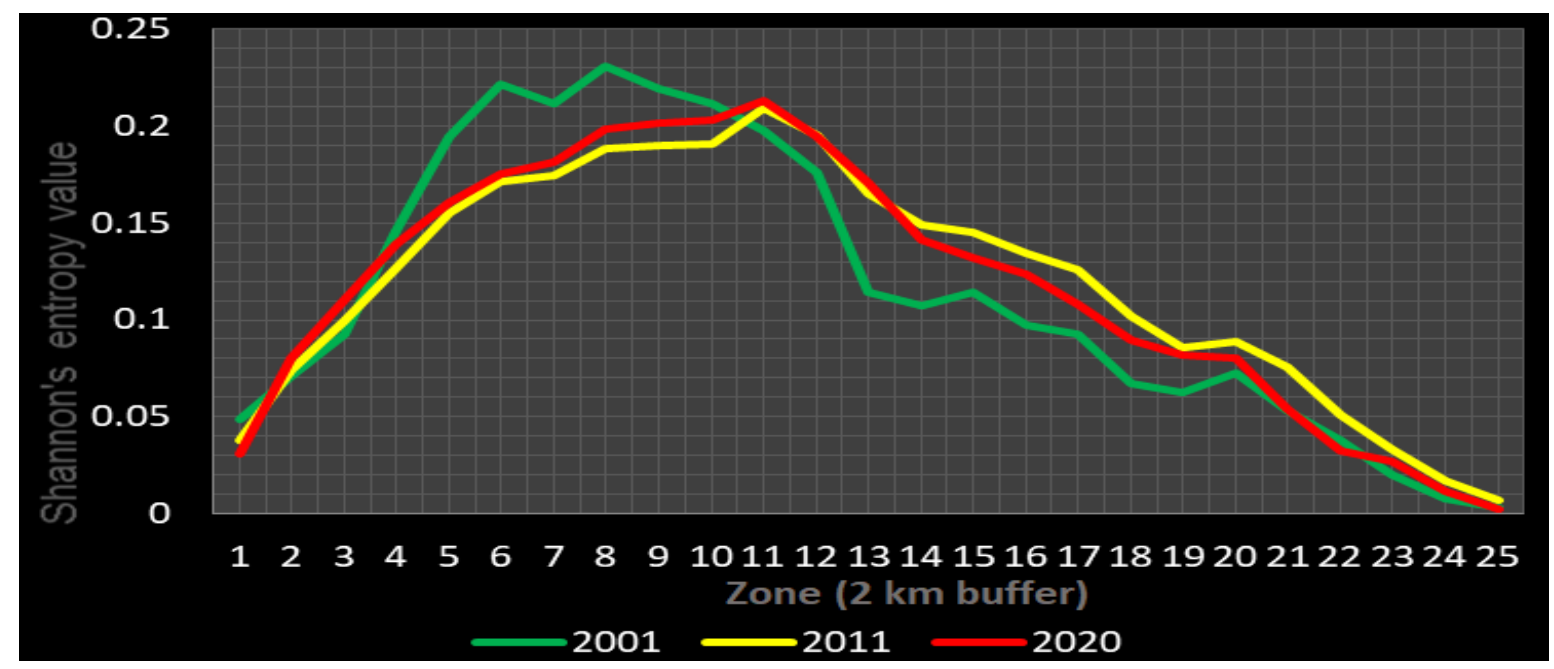

Figure 9. Zone wise value of Shannon's entropy in Bengaluru for the years 2001, 2010 and 2020.
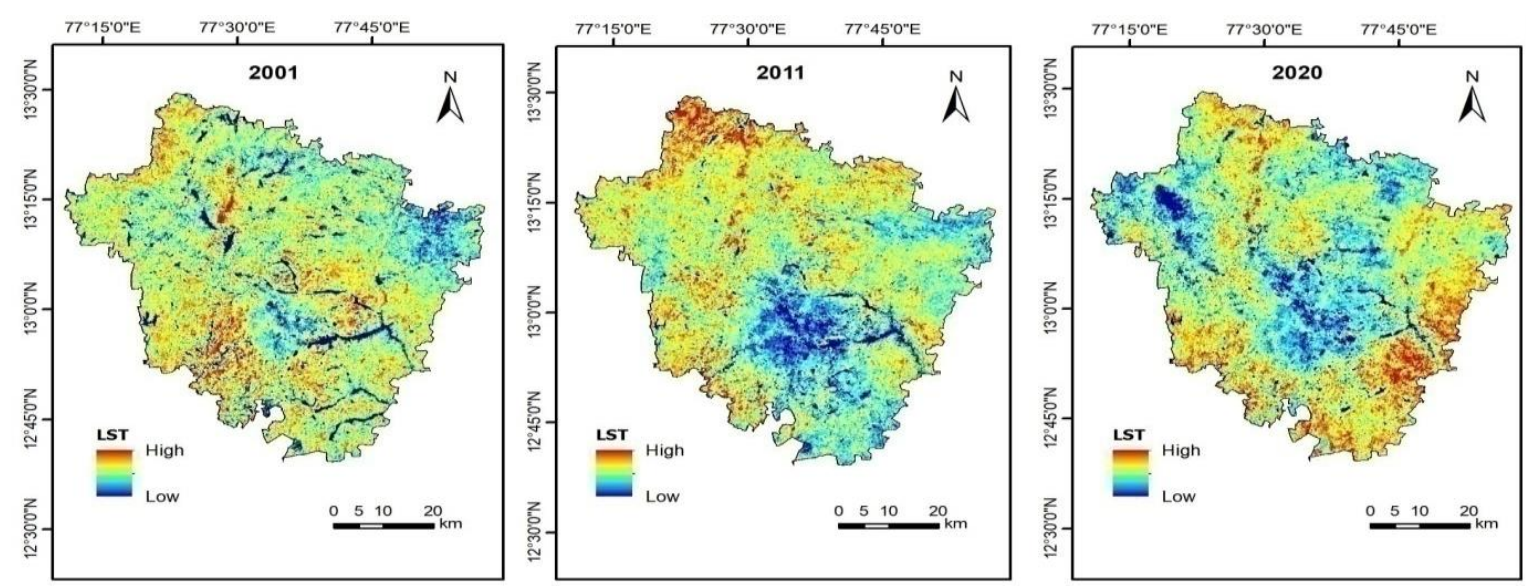

Figure 10. Spatio-temporal pattern of LST in Bengaluru.

share is increased in 2011 to $12.35 \%$. In the decade of 2001 to 2011, the urban area has a larger rise in comparison to the decade 2011 to 2020 . The area of vegetation reduced from $745.53 \mathrm{~km}^{2}$ to $245.12 \mathrm{~km}^{2}$ from 2001 to 2011 .

\begin{tabular}{|l|c|c|c|c|}
\hline \multicolumn{5}{|c|}{ From 2001 to 2011 } \\
\hline & Built-up & Vegetation & Open land & Water \\
\hline Built-up & 0.827 & 0.017 & 0.154 & 0.003 \\
Vegetation & 0.190 & 0.187 & 0.620 & 0.003 \\
Open land & 0.159 & 0.028 & 0.813 & 0.000 \\
Water & 0.113 & 0.144 & 0.471 & 0.272 \\
\hline \multicolumn{5}{|c|}{ From 2011 to 2020 } \\
\hline Built-up & 0.644 & 0.094 & 0.261 & 0.001 \\
Vegetation & 0.149 & 0.529 & 0.317 & 0.005 \\
Open land & 0.123 & 0.163 & 0.713 & 0.001 \\
Water & 0.564 & 0.173 & 0.022 & 0.241 \\
\hline
\end{tabular}

Table 5. Transition matrix of Bengaluru for the years 20012011 and 2011-2020.

As the crop harvesting time is in around March month so vegetation area looks like an open ground. Therefore, in the 2011 LULC image a significant drop happened in the vegetation area and it converted into an open ground due to harvesting. The interclass LULC changes are described by the transition matrix which is given in Table 5. A large percentage depicts that all the LULC classes are getting converted into the built-up class.

5.2.2 Shannon Entropy in Bengaluru: Buffer rings are created at $2 \mathrm{~km}$ intervals from the study area's centroid to the boundary after the urban area is extracted from the LULC classes, as shown in Figure 8 for 2001, 2011 and 2020. A total of 25 circular zones of $2 \mathrm{~km}$ buffer ring are created to cover the whole of the Bengaluru region for the urban sprawl measurement. Shannon's entropy value varies from 0 to $\log _{e}(n)$ (here $\left.n=25\right)$ i.e. from 0 to 3.219. Shannon's entropy value is 2.86 for the year 2001 and 2.99 for the year 2011 . This shows that an urban sprawl phenomenon because the values have increased. In 2020, Shannon's entropy value reduced to 2.92 , indicating that built-up development is experiencing compaction in the study area. Figure 9 shows the zone wise entropy for each year. In zone 1 to 11 , entropy values are higher for 2001 and lower for 2011. In zones 11 to 25 , the entropy graph shows the higher values for 2011 which indicates urban sprawl and lower values for 2020 which indicates the compaction in development pattern.

5.2.3 LST Change Analysis in Bengaluru: Figure 10 shows the spatial distribution of LST for the years 2001, 2011 and 2020. The minimum temperature and maximum temperature were recorded as $22^{\circ} \mathrm{C}$ and $41^{\circ} \mathrm{C}$, respectively, in 2001. In 2011, the minimum and maximum temperatures are 
$20^{\circ} \mathrm{C}$ and $46^{\circ} \mathrm{C}$, while for the year 2020 , their temperature is $20^{\circ} \mathrm{C}$ and $47^{\circ} \mathrm{C}$. Orange and red color indicates a higher temperature and blue color reflects low-temperature. In 2001, most of the pixels showed low and moderate temperature, but in the 2011 image, the higher temperature pixels are greater than the 2001 image. Some high-temperature pixels are noticeable outside the urban zone mainly in the southern part and north-west part of the study area. This has occurred as rock surfaces get more heated because of the sunlight. Most of the lower temperature pixels appear in the river area. Similar cold spots were obtained in other studies also (Govind and Ramesh, 2019). This is attributed to the presence of parks and lakes inside the city region.

\section{CONCLUSIONS}

The present study has shown the LULC, urbanization and LST changes in India's two major metropolitan cities. A massive jump in the built-up area is observed in both the study areas over the period of two decades. In this period, built-up has increased from $454.55 \mathrm{~km}^{2}$ to $803.05 \mathrm{~km}^{2}$ in Delhi while from $356.29 \mathrm{~km}^{2}$ to $1075.51 \mathrm{~km}^{2}$ in Bengaluru. This occurred at the cost of other LULC classes like vegetation, open land and water. The LULC analysis of Delhi has shown that the built-up area is increased by $76.67 \%$, the vegetated area is decreased by $15.01 \%$ and open land is reduced by $79.11 \%$. The same analysis on Bengaluru depicted that the built-up is increased by $201.86 \%$ and open land reduced by $20.81 \%$.

Shannon's entropy values have continuously increased from 2.456 to 2.466 for Delhi in the last two decades. It indicates the urban sprawl. In Bengaluru, Shannon's entropy value increased in 2001-2011 from 2.86 to 2.99 and decreased to 2.92 in 2020 . This reduction in the entropy value shows that compact development has been started in Bengaluru.

An increasing trend in the LST has been observed over the last two decades, displaying the effect of urban development on the local climate. The combined analysis of the LULC maps and LST information for every period has indicated that the temperature of the urban area increased due to the urban sprawl in Delhi and Bengaluru. The higher temperature zones can be linked to the built-up area in the study region and lower temperature zones to the vegetation or water body in the study area. This depicts the necessity to monitor and regulate urban sprawl at the expense of natural land covers to prevent altered urban climate and sustainability. This investigation can help in the planning of sustainable growth of metropolitan cities. The government and urban planners can make more informed decisions on controlling the changing LULC scenario and amplify the development of green infrastructure to reduce the effect of growing urbanization and LST.

\section{REFERENCES}

Agrawal, S., Gupta, R.D., 2017. Application of image analysis in land-use and land-cover assessment around schools for planning and development, Proceedings of the Computer Graphics International Conference. ACM, New York, NY, USA, 1-4. doi:10.1145/3095140.3095144

Agrawal, S., Khairnar, G.B., 2019. A comparative assessment of remote sensing imaging techniques: optical, SAR and LiDAR, Int. Arch. Photogramm. Remote Sens. Spatial Inf. Sci, XLII-5/W3, 1-6. doi:10.5194/isprs-archives-XLII-5-W3$1-2019$
Biney, E., Boakye, E., 2021. Urban sprawl and its impact on land use land cover dynamics of Sekondi-Takoradi metropolitan assembly, Ghana. Environ. Challenges 4, 100168. https://doi.org/10.1016/j.envc.2021.100168

Cilek, M.U., Cilek, A., 2021. Analyses of land surface temperature (LST) variability among local climate zones (LCZs) comparing Landsat-8 and ENVI-met model data. $\begin{array}{llll}\text { Sustain. } & \text { Cities } & \text { Soc. } & 69,\end{array}$ https://doi.org/10.1016/j.scs.2021.102877

Dutta, K., Basu, D., Agrawal, S., 2021. Synergetic interaction between spatial land cover dynamics and expanding urban heat islands. Environ. Monit. Assess. 193(4), 1-22. https://doi.org/10.1007/s10661-021-08969-4

Dutta, K., Basu, D., Agrawal, S., 2018. Temporal and spatial analysis of urban heat island using landsat satellite data: two Indian case studies. ISPRS Ann. Photogramm. Remote Sens. Spatial Inf. Sci, IV-5/W2, 71-78. doi:10.5194/isprs-annalsIV-5-71-2018

Falasca, S., Ciancio, V., Salata, F., Golasi, I., Rosso, F., Curci, G., 2019. High albedo materials to counteract heat waves in cities: an assessment of meteorology, buildings energy needs and pedestrian thermal comfort. Build. Environ. 163, 106242. https://doi.org/10.1016/j.buildenv.2019.106242

Govind, N.R., Ramesh, H., 2019. The impact of spatiotemporal patterns of land use land cover and land surface temperature on an urban cool island: a case study of Bengaluru. Environ. Monit. Assess. 191(5). https://doi.org/10.1007/s10661-019-7440-1

Hua, L., Wang, M., Zhao, X., 2012. Temporal and spatial characteristics of urban heat island of an estuary city, China. $\begin{array}{lll}\text { J. } & \text { Comput. 3082-3087. }\end{array}$ https://doi.org/10.4304/jcp.7.12.3082-3087

Mahmoodi, S., Dutta, K., Basu, D., Agrawal, S., 2019. Understanding link between land surface temperature and landscape heterogeneity: a spatio-temporal and inter-seasonal variability study on Kabul city, Afghanistan, ISPRS Ann. Photogramm. Remote Sens. Spatial Inf. Sci, IV-5/W2, 57-65. doi:10.5194/isprs-annals-IV-5-W2-57-2019

Oke, T.R., 1973. City size and the urban heat island. Atmos. Environ. 7(8), 769-779. https://doi.org/10.1017/CBO9781107415324.004

Ramachandra, T. V., Kumar, U., 2009. Land surface temperature with land cover dynamics: multi-resolution, spatio-temporal data analysis of greater Bangalore, India. Int. J. Geoinformatics 5(3), 43-53.

Saha, P., Bandopadhyay, S., Kumar, C., Mitra, C., 2020. Multi-approach synergic investigation between land surface temperature and land-use land-cover. J. Earth Syst. Sci. 129(1). https://doi.org/10.1007/s12040-020-1342-Z

Shastri, H., Barik, B., Ghosh, S., Venkataraman, C., Sadavarte, P., 2017. Flip flop of day-night and summerwinter surface urban heat island intensity in India. Sci. Rep. 7(1), 1-8. https://doi.org/10.1038/srep40178

Sultana, S., Satyanarayana, A.N.V., 2020. Assessment of urbanisation and urban heat island intensities using Landsat imageries during 2000 - 2018 over a sub-tropical Indian city. Sustain. $\quad$ Cities $\quad$ Soc. $\quad 52, \quad 101846$. https://doi.org/10.1016/j.scs.2019.101846 